\title{
Site heteroplasmy in the mitochondrial cytochrome b gene of the sterlet sturgeon Acipenser ruthenus
}

\author{
Andreea Dudu ${ }^{1}$, Sergiu Emil Georgescu ${ }^{1}$, Patrick Berrebi ${ }^{2}$ and Marieta Costache ${ }^{1}$ \\ ${ }^{1}$ Department of Biochemistry and Molecular Biology, University of Bucharest, Bucharest, Romania. \\ ${ }^{2}$ Institut des Sciences de l'Evolution, University Montpellier II, Montpellier, France.
}

\begin{abstract}
Sturgeons are fish species with a complex biology. They are also characterized by complex aspects including polyploidization and easiness of hybridization. As with most of the Ponto-Caspian sturgeons, the populations of Acipenser ruthenus from the Danube have declined drastically during the last decades. This is the first report on mitochondrial point heteroplasmy in the cytochrome b gene of this species. The $1141 \mathrm{bp}$ sequence of the cytb gene in wild sterlet sturgeon individuals from the Lower Danube was determined, and site heteroplasmy evidenced in three of the 30 specimens collected. Two nucleotide sequences were identified in these heteroplasmic individuals. The majority of the heteroplasmic sites are synonymous and do not modify the sequence of amino acids in cytochrome $B$ protein. To date, several cases of point heteroplasmy have been reported in animals, mostly due to paternal leakage of mtDNA. The presence of specific point heteroplasmic sites might be interesting for a possible correlation with genetically distinct groups in the Danube River.
\end{abstract}

Key words: sterlet sturgeon, mtDNA, site heteroplasmy.

Received: December 20, 2011; Accepted: July 5, 2012.

The vertebrate mitochondrial genome presents certain features, such as compact organization, maternal transmission, relatively small size, hundreds to thousands of copies per cell, rapid evolution, and a lack of or much reduced recombination, which recommend it as a useful tool for studies on population genetics, phylogeny and phylogeography. Although mitochondrial DNA (mtDNA) haplotype frequencies were long considered to be primarily controlled by migration and genetic drift, and most intraspecies variation to be selectively neutral (Ballard and Rand 2005), there are more recent indications of the possible recombination of mtDNA in various species (Tsaousis et al., 2005; Guo et al., 2006). Thus, mtDNA variation could be a consequence of simple neutral mutation and genetic drift (Wallace et al., 2003; Ruiz-Pesini et al., 2004). mtDNA heteroplasmy, i.e. the presence of multiple mtDNA haplotypes in a single organism, is not an exceptional condition related to mitochondrial disease (Monnat $\mathrm{Jr}$ and Loeb, 1985), and many cases of healthy heteroplasmic individuals have been described (Brandstatter et al., 2004; Santos et al., 2005).

Depending on the type of mtDNA mutation, two types of heteroplasmy are known, site (point) and length

Send correspondence to Marieta Costache. Department of Biochemistry and Molecular Biology, University of Bucharest, Splaiul Independentei 91-95, 050095 Bucharest 5, Romania. E-mail: marietacostache@yahoo.com. heteroplasmy. Length heteroplasmy occurs in hypervariable regions of the D-loop as a consequence of poor replication fidelity, and is represented by multiple mtDNA populations of various lengths. Point heteroplasmy is represented by the presence of various mtDNA populations differing from each other at a given nucleotide position. This is a less frequent phenomenon and is considered to be a transient state regarding the fixation of either the wild type or the mutated type (Santos et al., 2005, 2008; Irwin et al., 2009). Apparently, in cattle, mice and humans, heteroplasmy is generally resolved to homoplasmy within a few generations (Chinnery, 2002; Cree et al., 2008; Khrapko, 2008).

The Acipenseriformes constitute one of the oldest groups of fish, having appeared 200 million years ago, during the Jurassic period (Bemis et al., 1997). Since these are among the oldest fish species, having survived several mass extinction events, and are authentic "living fossils" with a slow evolution, sturgeons may constitute a model for studying vertebrate development. Acipenser ruthenus Linnaeus, 1758 (Sterlet) is a freshwater species and is the smallest species of sturgeon. Originally it was widely distributed in the tributaries flowing into the Caspian, Black, Azov, Baltic, White, Barents and Kara Seas. The Danube is a stronghold for the species, and in recent years, catches have been reported as far upstream as Austria.

mtDNA heteroplasmy is frequent in fish and has been identified in several species, such as Cyprinella spiloptera 
(Broughton and Dowling, 1994), Gadus morhua (Arnason and Rand, 1992) Oncorhynchus tschawytscha, Oncorhynchus keta (Cronin et al., 1993, Shigenbou et al., 2005), Perca fluviatilis, Acerina cernua, Stizostedion lucioperca (Nesbø et al., 1998) and Paralichthys olivaceus (Shigenbou et al., 2005). Although length heteroplasmy of the control region in sturgeons has been identified (Brown et al., 1996; Zhang et al., 1999; Ludwig et al., 2000), to date, there are no reports on site heteroplasmy.

In this survey, the intention was to describe $A$. ruthenus heteroplasmy and present hypotheses on its origin and evolution.

Small fin fragments from 30 wild individuals of $A$. ruthenus captured in the Lower Danube (Romania). Total DNA was extracted according to the method described by Taggart et al., (1992) with minor modifications.

Amplification was carried out in a $25 \mu \mathrm{L}$ final volume consisting of 40-50 ng DNA, 10 pmols of each primer, $100 \mu \mathrm{M}$ of each dNTP, $1.5 \mathrm{mM} \mathrm{MgCl}_{2}$ and 1 unit of AmpliTaq Gold DNA Polymerase (Applied Biosystems). A combination of two sets of primers designed for cyprinid fish species (Zardoya and Doadrio 1995) was used for amplification of the cytochrome b gene: Glu-F: 5'gaagaaccaccgttgttattcaa-3'; Cytb-R: 5'-tctttatatgagaartan gggtg-3'; Cytb-F: 5'-cacgaracrggrtcnaayaa-3'; Thr-R: 5'-acctccratctycggattaca-3'. These are versatile primers designed for highly conserved fish mitochondrial DNA sequences around and within the cytb gene, and which amplify the two contiguous and overlapping fragments that cover the entire cytb gene (1141 bp). The specific annealing temperature for each set of primers, determined by gradient temperature PCR, was $48{ }^{\circ} \mathrm{C}$ for Glu-F/Cytb-R and $56{ }^{\circ} \mathrm{C}$ for Cytb-F/Thr-R. Amplifications were carried out in the GeneAmp PCR System 9700 (Applied Biosystems), under the following conditions: first denaturation step $10 \mathrm{~min}$ at $95^{\circ} \mathrm{C}, 35$ cycles - denaturation $\left(30 \mathrm{~s}\right.$ at $\left.95^{\circ} \mathrm{C}\right)$, annealing (30 s at annealing temperature), extension $\left(60 \mathrm{~s}\right.$ at $\left.72{ }^{\circ} \mathrm{C}\right)$ and a final polymerization step at $72{ }^{\circ} \mathrm{C}$ for $10 \mathrm{~min}$. The PCR products were purified with Wizard SV Gel and PCR Clean-Up System (Promega), sequenced with Big Dye Ter- minator v3.1 kit (Applied Biosystems) and analyzed on a ABI3130 DNA Genetic Analyzer (Applied Biosystems).

The electropherograms were first visualized and analyzed with Sequence Analysis Software (Applied Biosystems), and the sequences then edited with BioEdit Sequence Alignment Editor (Hall 1999). Multiple alignment of nucleotide sequences were carried out with the Clustal W program (Thompson 1994). We determined the 1141 bp sequence of cytb gene in A. ruthenus from the Lower Danube. Through electrophoregram analysis, double-peak sites were identified in several different positions in this gene, in three of the 30 specimens. These double peaks were confirmed by both $5^{\prime} \rightarrow 3^{\prime}$ and $3^{\prime} \rightarrow 5^{\prime}$ ' strands and are an indication of point heteroplasmy in this gene (Figure 1). The experiment was repeated from DNA extraction until sequences analysis. All the sequences, including double peaks, were identical. Two nucleotide sequences were identified in the heteroplasmic individuals: AruH1 was observed in two of the three heteroplasmic individuals, while AruH2 was observed in one individual (Table 1). The two detected sequences differed by three polymorphic sites. Thus, AruH1 was defined by the heteroplasmic site $867 \mathrm{C} / \mathrm{T}$, and $\mathrm{AruH} 2$ by $867 \mathrm{~T}$. Apart from the polymorphism in position 867, two transitions, 399G/A and $585 \mathrm{C} / \mathrm{T}$, were spotted between AruH1 and AruH2 (Figure 2).

Among the 27 non-heteroplasmic individuals, 3 haplotypes were identified based on the polymorphisms corresponding to bases 399 and 585. Thus, one individual presented the haplotype AruH3, three individuals presented the haplotype AruH4 and 23 presented the haplotype AruH5 (Table 1).

A homology search done by using a sequence of $A$. ruthenus from GenBank (AJ249694), facilitated the identification of codons displaying such heteroplasmic sites and the corresponding putative amino acids. Most of the identified heteroplasmic sites are synonymous, which means that the transition to homoplasmy and the fixation of any of the two nucleotide variants will not modify the amino acids sequence in cytochrome B protein (Table 1). The exception is

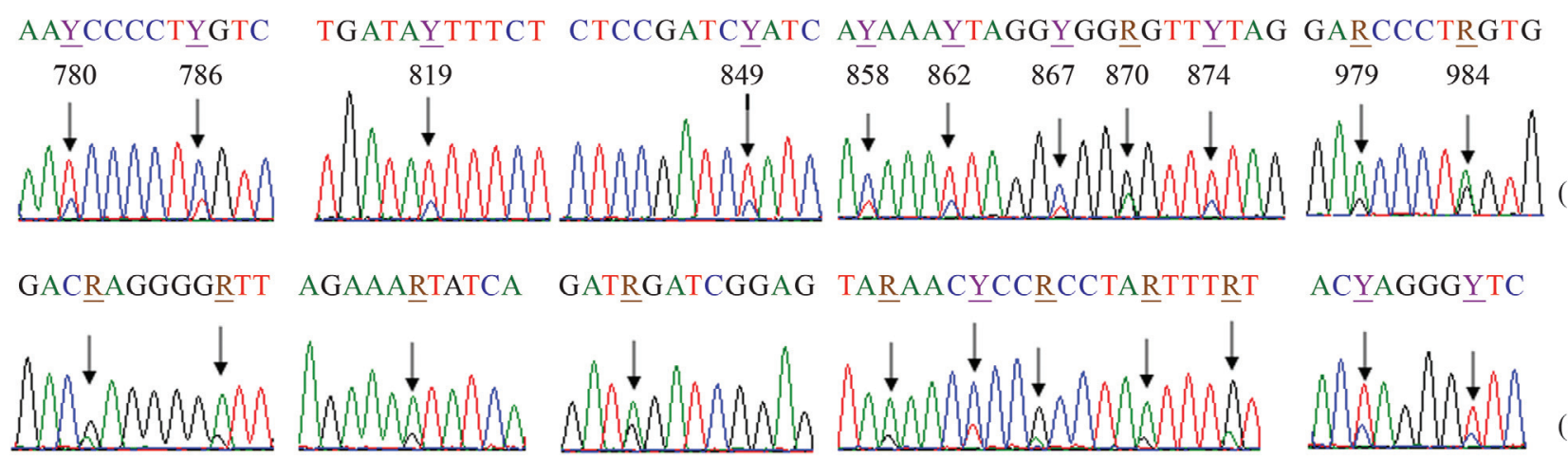

Figure 1 - Partial sequence electropherograms of cytochrome b in A. ruthenus. (1) 5' $\rightarrow$ 3' strand; (2) 3' $\rightarrow 5^{\prime}$ ' strand. $\mathrm{R}=\mathrm{A} / \mathrm{G} ; \mathrm{Y}=\mathrm{C} / \mathrm{T}$. 


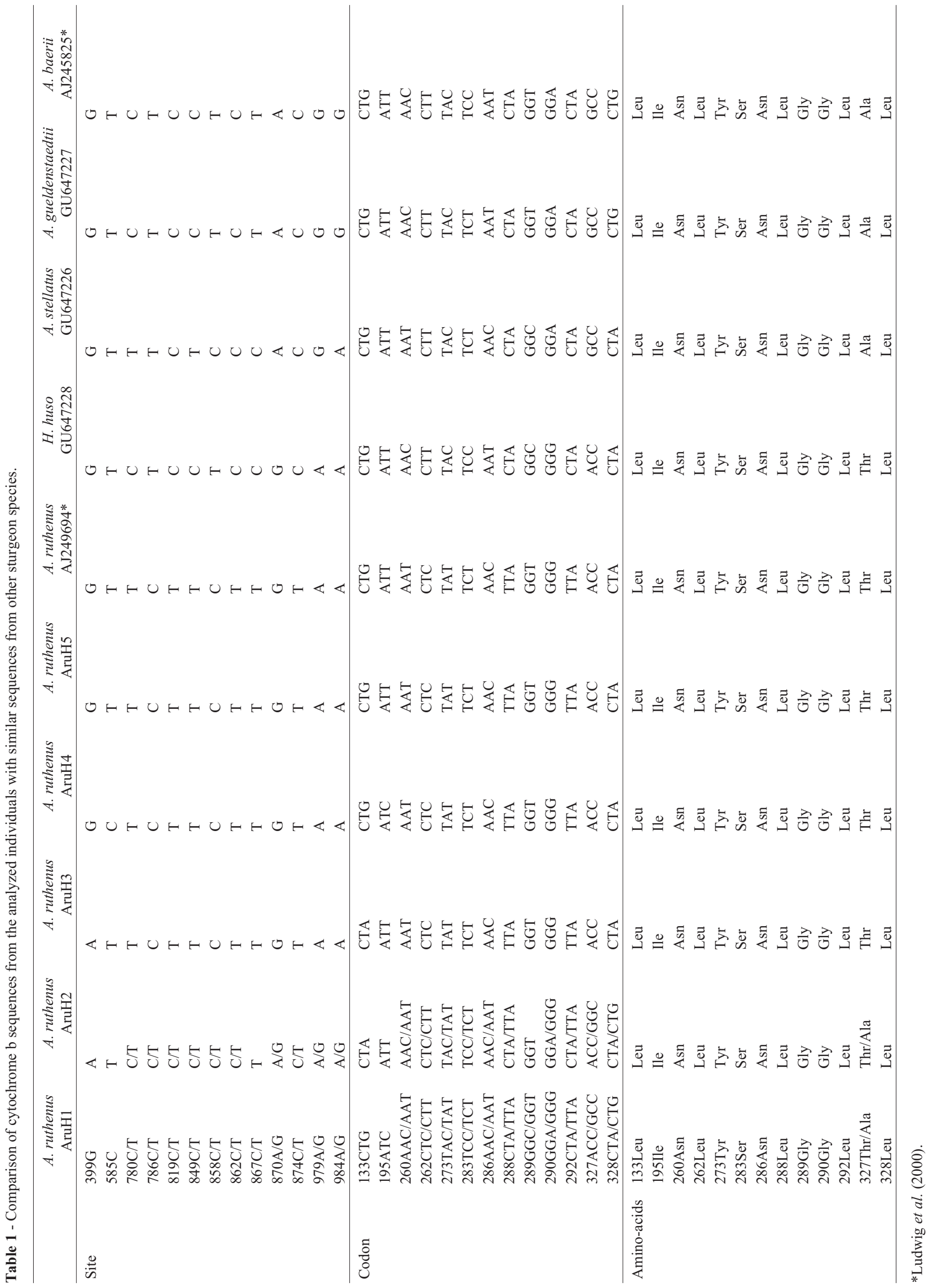



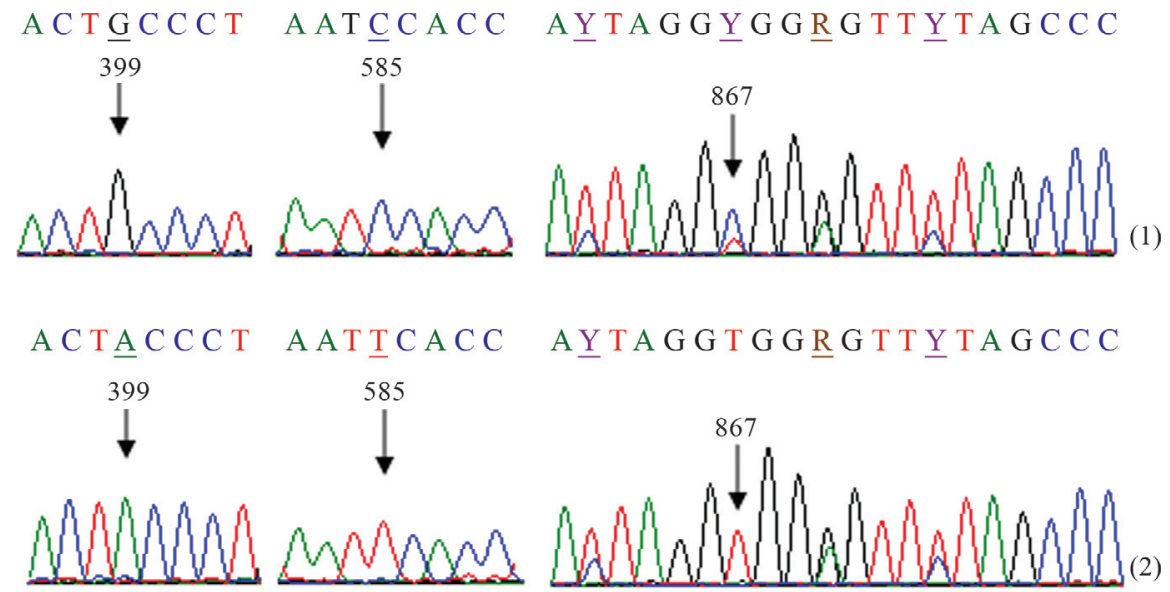

Figure 2 - Partial sequence electropherograms of cytochrome b in A. ruthenus (5' $\rightarrow$ 3' strand) differentiating between AruH1 (1) and AruH2 (2). $\mathrm{R}=\mathrm{A} / \mathrm{G} ; \mathrm{Y}=\mathrm{C} / \mathrm{T}$

the double peak $979 \mathrm{~A} / \mathrm{G}$ in the first position of codon 327 , corresponding to the putative amino acids, Thr or Ala.

Comparative sequence analysis of mitochondrial protein-coding genes in closely related species of salmonids (Doiron et al., 2002) and mammals (Pesole et al., 1999), revealed nucleotide substitution frequencies at non-synonymous sites to be 8 to 30 times lower than at synonymous sites (Shigenbou et al., 2005). Non-synonymous heteroplasmic sites have been observed in fish in the NADH dehydrogenase subunit-5 (nd5) gene of chum salmon and in the NADH dehydrogenase subunit-4 gene (nd4) of the Japanese flounder (Shigenbou et al., 2005). The comparison of amino acid sequences among other sturgeon species revealed that, in the case of the non-synonymous heteroplasmy site, both putative variants of amino acids were identified, thereby showing them to be viable and functional (Table 1).

Although relatively rare, cases of point heteroplasmy have been reported in animals. Amongst others factors, this can be due to interspecific paternal leakage. The biparental inheritance of mtDNA has been revealed in various species, including fish (Guo et al., 2006; Magoulas and Zouros, 1993). Most cases of paternal leakage derive from interspecies hybridization, backcrosses and introgression, probably due to the breakdown of mechanisms recognizing and removing paternal mtDNA (Sutovsky et al., 2003; White et al., 2008). In sturgeons, interspecific hybridization is a relatively frequent phenomenon, mostly due to the temporal and spatial overlapping of breeding areas. Apart from $A$. ruthenus, three other sturgeon species are currently reproducing in the Lower Danube: A. stellatus, $A$. gueldenstaedtii and $H$. huso. Due to both natural and anthropogenic factors, hybridization between these three species and sterlet sturgeons is highly possible (Dudu et al., 2011). Moreover, there have been reported cases of hybridization between $A$. ruthenus and the exotic species $A$. baerii (the Siberian sturgeon, bred in local fish farms) in the Danube River (Ludwig et al., 2009). Under these circum- stances, heteroplasmic sites are possibly signals of introgressive hybridization. By analyzing the sequence variation shown in Table 1 we consider that the observed heteroplasmy is the result of interspecific hybridization of A.ruthenus individuals in the Danube River. In populations that suffered a bottleneck event, a mitochondrial haplotype from one of the genitor species might become dominant in the cells of the other species, passing through a transitional state of heteroplasmy. This type of mtDNA transfer was proposed by Billard and Lecointre (2001), Doyle (1997) and Maddison (1997) as justifying the close relationship found between A. ruthenus and H.huso, as based on cytb and 12S/16S rRNA sequences (Birstein and DeSalle, 1998).

Due to the risk of detecting heteroplasmic signals in the absence of true heteroplasmy, careful screening should be the rule. The cause of amplification artifacts is correlated with either the existence of nuclear-encoded mitochondrial pseudogenes (or NUMTs), or the presence of duplications within mitochondrial genomes (White et al., 2008). In species harbouring NUMTs, PCR primers may hybridize to both mitochondrial sequences and nuclear copies. The resulting co-amplifications can be mistakenly recognised as heteroplasmic sites, or lead to inaccurate estimates of heteroplasmy levels (White et al., 2008).

This is the first report on point heteroplasmy in a coding mitochondrial region of $A$. ruthenus. The recombination of mtDNA has a great importance and should be considered for the accuracy of population studies and phylogenetic reconstruction in this group of fish, also taking into account other aspects such as hybridization or introgression. As hybridization among Danubian sturgeons has been the target of several surveys (Ludwig et al., 2009; Dudu et al., 2011), a heteroplasmy description could be a possible aid in its determination. In A. ruthenus the identification of specific point heteroplasmic sites might be interesting for a possible correlation of these haplotypes with genetically distinct groups in the Danube River. 


\section{Acknowledgments}

$\mathrm{AD}$ is a $\mathrm{PhD}$ student supported by a fellowship from the ESF project "Financial support for doctoral studies on the complexity of nature, environment and human society" POSDRU/6/1.5/S/24, coordinated by AMPOSDRU, Ministry of Labour, Family and Social Protection, Romania, the bilateral project Romania-France 484/2011 "Diversité génétique et hybridation des esturgeons de Roumanie et de France" and the PN-II-PT-PCCA Project 116/2012 "Genetic evaluation and monitoring of molecular and biotechnological factors that influence productive performance of Danube sturgeon species bred in intensive recirculating systems".

\section{References}

Arnason E and Rand DM (1992) Heteroplasmy of short tandem repeats in mitochondrial DNA of Atlantic cod, Gadus morhua. Genetics 132:211-220.

Ballard JWO and Rand DM (2005) The population biology of mitochondrial DNA and its phylogenetic implications. Annu Rev Ecol Evol Syst 36:621-642.

Bemis WE, Findeis EK and Grande L (1997) An overview of Acipenseriformes. In: Birstein VJ, Waldman JR and Bemis WE (eds) Sturgeon Biodiversity and Conservation. Kluwer Academic Publishers, Dordrecht, pp 25-71.

Billard R and Lecointre G (2001) Biology and conservation of sturgeon and paddlefish. Rev Fish Biol Fisher 10:355-392.

Birstein VJ and DeSalle R (1998) Molecular phylogeny of Acipenserinae. Mol Phylogenet Evol 9:141-155.

Brandstatter A, Niederstatter H and Parson W (2004) Monitoring the heteroplasmy by computer-assisted detection of mixed basecalls in the entire human mitocondrial DNA control region. Int J Legal Med 118:47-54.

Broughton RE and Dowling TE (1994) Length variation in mitochondrial DNA of the Minnow Cyprinella spiloptera. Genetics 138:179-190.

Brown JR, Beckenbach K, Beckenbach AT and Smith MJ (1996) Length variation, heteroplasmy and sequence divergence in the mitochondrial DNA of four species of sturgeon (Acipenser). Genetics 142:525-535.

Chinnery PF (2002) Modulating heteroplasmy. Trends Genet 18:173-176.

Cree LM, Samuels DC, de Sousa Lopes SC, Rajasimha HK and Wonnapinij P (2008) A reduction of mitochondrial DNA molecules during embryogenesis explains the rapid segregation of genotypes. Nat Genet 40:249-254.

Cronin MA, Spearman WJ, Wilmot RL, Patton JC and Bickham JW (1993) Mitochondrial DNA variation in chinook (Oncorhynchus tshawytscha) and chum salmon (Oncorhynchus keta) detected by restriction enzyme analysis of polymerase chain reaction (PCR) products. Can J Fish Aquat Sci 50:708-715.

Doiron S, Bernatchez L and Blier PU (2002) A comparative mitogenomic analysis of the potential adaptative value of arctic charr mtDNA introgression in brook charr populations (Salvelinus fontinalis Mitcnill). Mol Biol Evol 19:19021909.
Doyle JJ (1997) Trees within trees: Genes and species, molecules and morphology. Syst Biol 46:537-553.

Dudu A, Suciu R, Paraschiv M, Georgescu SE, Costache M and Berrebi P (2011) Nuclear markers of Danube sturgeons hybridization. Int J Mol Sci 12:6796-6809.

Guo X, Liu S and Liu Y (2006) Evidence for recombination of mitochondrial DNA in triploid crucian carp. Genetics 172:1745-1749.

Hall TA (1999) BioEdit: A user-friendly biological sequence alignment editor and analysis program for Windows 95/98/NT. Nucleic Acids Symp Ser 41:95-98.

Irwin JA, Saunier JL, Niederstätter H, Strouss KM, Sturk KA, Diegoli TM, Brandstätter A, Parson W and Parsons TJ (2009) Investigation of heteroplasmy in the human mitochondrial DNA control region: A synthesis of observations from more than 5000 global population samples. J Mol Evol 68:516-527.

Khrapko K (2008) Two ways to make an mtDNA bottleneck. Nat Genet 40:134-135.

Ludwig A, May B, Debus L and Jenneckens I (2000) Heteroplasmy in the mtDNA Control Region of Sturgeon (Acipenser, Huso and Scaphirhynchus). Genetics 156:1933-1947.

Ludwig A, Lippold S, Debus L and Reinartz R (2009) First evidence of hybridization between endangered sterlets (Acipenser stellatus) and exotic Siberian sturgeons (Acipenser baerii) in the Danube River. Biol Invasions 11:753-760.

Maddison WP (1997) Gene trees in species trees. Syst Biol 46:523-536.

Magoulas A and Zouros E (1993) Restriction-site heteroplasmy in Anchovy (Engraulis encrasicolus) indicates incidental biparental inheritance of mitochondrial DNA. Mol Biol Evol 10:319-325.

Monnat Jr RJ and Loeb LA (1985) Nucleotide sequence preservation of human mitochondrial DNA. Proc Natl Acad Sci USA 82:2895-2899.

Nesbø CL, Arab MO and Jakobsen KS (1998) Heteroplasmy, length and sequence variation in the mtDNA control regions of three percid fish species (Perca fluviatilis, Acerina cernua, Stizostedion lucioperca). Genetics 148:1907-1919.

Pesole G, Gissi C, Chirrico AD and Saccone C (1999) Nucleotide substitution rate of mammalian mitochondrial genomes. J Mol Evol 48:427-434.

Ruiz-Pesini E, Mishmar D, Brandon M, Procaccio V and Wallace DC (2004) Effects of purifying and adaptive selection on regional variation in human mtDNA. Science 303:223-226.

Santos C, Montiel R, Sierra B, Bettencourt C, Fernandez E, Alvarez L, Lima M, Abade A and Aluja MP (2005) Understanding differences between phylogenetic and pedigreederived mtDNA mutation rate: A model using families from the Azores Islands (Portugal). Mol Biol Evol 22:1490-1505.

Santos C, Sierra B, Álvarez L, Ramos A, Fernández E, Nogués R and Aluja MP (2008) Frequency and pattern of heteroplasmy in the control region of human mitochondrial DNA. J Mol Evol 67:191-200.

Shigenbou Y, Saitoh K, Hayashizaki K and Hitoshi I (2005) Nonsynonymous site heteroplasmy in fish mitochondrial DNA. Genes Genet Syst 80:297-301.

Sutovsky P, McCauley TC, Sutovsky M and Day BN (2003) Early degradation of paternal mitochondria in domestic pig (Sus scrofa) is prevented by selective proteasomal inhibitors lactacystin and MG132. Biol Reprod 68:1793-1800. 
Taggart JB, Hynesp A, Prodohl A and Ferguson A (1992) A simplified protocol for routine total DNA isolation from salmonid fishes. J Fish Biol 40:963-965.

Thompson JD (1994) CLUSTAL W: Improving the sensitivity of progressive multiple sequence alignment through sequence weighting, position-specific gap penalties and weight matrix choice. Nucleic Acids Res 22:4673-4680.

Tsaousis AD, Martin DP, Ladoukakis ED, Posada D and Zouros E (2005) Widespread recombination in published animal mtDNA sequences. Mol Biol Evol 22:925-933.

Wallace DC, Ruiz-Pesini E and Mishmar D (2003) mtDNA variation, climatic adaptation, degenerative diseases, and longevity. Cold Spring Harbor Symp Quant Biol 68:479-486.
White DJ, Wolff JN, Pierson M and Gemmell NJ (2008) Revealing the hidden complexities of mtDNA inheritance. Mol Ecol 17:4925-4942.

Zardoya R and Doadrio I (1995) Phylogenetic relationships of Iberian cyprinids: Systematic and biogeographical implications. Proc R Soc Lond B 265:1365-1372.

Zhang SM, Deng H, Wang DQ, Zhang YP and Wu QJ (1999) Mitochondrial DNA length variation and heteroplasmy in Chinese sturgeon (Acipenser sinensis). Acta Genet Sin 26:489496.

Associate Editor: Antonio Matteo Solé-Cava

License information: This is an open-access article distributed under the terms of the Creative Commons Attribution License, which permits unrestricted use, distribution, and reproduction in any medium, provided the original work is properly cited. 